\title{
Epidemiological treatment of sexual contacts prevents recurrence of non-gonococcal urethritis
}

\author{
P D WOOLLEY, J D WILSON, G R KINGHORN \\ From the Department of Genitourinary Medicine, Royal Hallamshire Hospital, Sheffield
}

SUMMARY Of 98 male patients with non-gonococcal urethritis (NGU) who had regular female consorts who received concurrent epidemiological treatment, NGU recurred in four $(16 \%)$ men whose treated partners were initially chlamydia positive and $20(27 \%)$ men whose treated partners were initially chlamydia negative. Of 32 men whose regular female sexual partners refused to attend, $26(77 \%)$ men suffered a recurrence of NGU. All study patients were selected because they were in monogamous relationships and returned to the clinic either because of a recurrence of NGU or for unrelated reasons at least 12 months after treatment. We recommend the routine epidemiological treatment of all sexual contacts of men with NGU.

Although Sheffield had a mean outward migration of 25.7 per 1000 in $1975-80$ for a population of 543700 (National Health Service Central Register, Office of Population Censuses) and thus appears to have a stable population, this does not take into account the type of patients seen with non-gonococcal urethritis (NGU) who are often young, single, and working outside the local area. As a result, patients who do not attend cannot be assumed to be free from recurrent disease.

Despite strong evidence for a microbial cause of NGU, ${ }^{12}$ several studies undertaken to assess the effects of epidemiological treatment of sexual contacts have shown no reduction in the recurrence rate in men whose sexual partners have been treated..$^{3-5}$ These studies, however, have not been able to surmount the problem of long term follow up or the possibility of re-exposure to an untreated partner or exposure to a new infected partner. To evaluate the effect of concurrent treatment of consorts on the recurrence rate of NGU in men, our study looked at the case records of male patients who re-attended the clinic after their first ever episode of urethritis either with their first recurrence or, at least 12 months later, for other reasons, and who had had the same regular female sexual partner and no casual partners since their first attendance.

At each new attendance we took a full sexual history from all new male patients. Investigation consis-

Address for reprints: Dr P D Woolley, Department of Genitourinary Medicine, Royal Hallamshire Hospital, Glossop Road, Sheffield S10 2JF.

Accepted for publication 1 February 1987 ted of microscopy of a Gram stained urethral smear for Neisseria gonorrhoeae and to count polymorphonuclear leucocytes (PMNL), culture for $N$ gonorrhoeae, wet mount microscopy for Trichomonas vaginalis and yeasts, and serological tests for syphilis. All new female patients additionally had urethral and cervical swabs taken for culture for Chlamydia trachomatis. The diagnosis of NGU was made on the basis of more than 8 PMNL per high power field $(\times 1000)$ in a Gram stained urethral smear, negative wet mount microscopy, negative culture for $N$ gonorrhoeae, and the absence of either intrameatal warts or genital herpes. ${ }^{6}$ All men with NGU were treated with a three week course of triple tetracycline (Deteclo) $300 \mathrm{mg}$ twice daily, and were assessed after treatment and again four weeks later. Epidemiological treatment was offered to all female sexual consorts who attend the clinic.

\section{Patients and methods}

PATIENTS

In 1981 to 1984787 heterosexual men (mean age 28) attended the department of genitourinary medicine in Sheffield with their first ever episode of urethritis, and also re-attended with their first recurrence of NGU or, after a minimum of 12 months had elapsed, for other reasons. Patients developing seronegative arthropathy or prostatitis were excluded. Of the 787 men, $622(79 \%)$ had had either a change of sexual partner or an additional casual partner before reattending the clinic. Of the remaining 165 patients, 15 had not had any sexual contact since their first attendance, six had female consorts who had had an addi- 
tional partner, and 12 had female consorts who had new infections with either $C$ trachomatis or $T$ vaginalis at re-attendance, which suggested that a third party had caused reinfection. The other 132 patients, for whom there was no evidence that they or their consorts had been exposed to other sexual partners since their first attendance, and who lived in the Sheffield catchment area, were the basis of this study. Their clinical records were reviewed for accuracy of the initial diagnosis, reasons for re-attendance, information regarding sexual contacts, and to ensure that both partners were treated concurrently.

\section{STATISTICAL METHODS}

Groups were compared by $\chi^{2}$ tests using Yates's correction for $2 \times 2$ tables.

\section{Results}

Of the 132 study patients, 98 had female consorts who received concurrent epidemiological treatment for NGU and 34 had consorts who refused to attend and remained untreated. $C$ trachomatis was isolated from the treated partners of 25 men.

The table shows that NGU recurred in four $(16 \%)$ men whose treated partners were initially chlamydia positive, $20(27 \%)$ men whose treated partners were initially chlamydia negative, and $26(77 \%)$ men with untreated consorts. The difference in recurrence rate between those with chlamydia associated and chlamydia negative NGU was not significant. In both groups of men with treated partners, however, the recurrence rate was significantly less than in men with untreated partners $(\mathrm{p}>0.001)$.

The mean time to first recurrence was, for men with chlamydia associated NGU 7.5 months, with chlamydia negative NGU 9.8 months, and with untreated consorts 6.4 months. There was no significant

Table Effect of epidemiological treatment of female consorts on recurrences of NGU in 132 men

\begin{tabular}{|c|c|c|c|}
\hline & \multicolumn{2}{|c|}{$\begin{array}{l}\text { Female consorts treated } \\
\text { and: }\end{array}$} & \multirow{2}{*}{$\begin{array}{l}\text { Female } \\
\text { consorts } \\
\text { untreated }\end{array}$} \\
\hline & $\begin{array}{l}\text { Chlamydia } \\
\text { associated }\end{array}$ & $\begin{array}{l}\text { Chlamydia } \\
\text { negative }\end{array}$ & \\
\hline $\begin{array}{l}\text { No of men } \\
\text { Mean age (years) } \\
\text { Age range (years) } \\
\text { Marital status: }\end{array}$ & $\begin{array}{l}25 \\
22 \\
17-27\end{array}$ & $\begin{array}{l}73 \\
28 \\
17-47\end{array}$ & $\begin{array}{l}34 \\
26 \\
19-39\end{array}$ \\
\hline $\begin{array}{l}\text { No }(\%) \text { single } \\
\text { No }(\%) \text { married } \\
\text { No }(\%) \text { white } \\
\text { No }(\%) \text { with a recurrence } \\
\text { Mean time to first }\end{array}$ & $\begin{array}{r}24(96) \\
1(4) \\
23(92) \\
4(16)\end{array}$ & $\begin{array}{l}48(66) \\
25(34) \\
69(95) \\
20(27)\end{array}$ & $\begin{array}{r}25(74) \\
9(27) \\
32(94) \\
26(77)\end{array}$ \\
\hline $\begin{array}{l}\text { recurrence (months) } \\
\text { No }(\%) \text { free from }\end{array}$ & $7 \cdot 5$ & $9 \cdot 8$ & 6.4 \\
\hline recurrence & $21(84)^{*}$ & $53(73) \dagger$ & $8(24)$ \\
\hline
\end{tabular}

${ }^{*} \chi^{2}=18 \cdot 7 ; \dagger \chi^{2}=20 \cdot 8 ; p>0.001$. difference in either mean age or marital status between men with and without recurrences of NGU (data not shown). Men with chlamydia associated NGU were younger (mean age 22) than men with chlamydia negative NGU (mean age 28 ). The proportion of single men was higher in men with chlamydia associated NGU $(96 \%, 24 / 25)$ than in those with chlamydia negative NGU $(65 \%, 48 / 73)$.

\section{Discussion}

Prospective studies to assess the effects of epidemiological treatment of sexual contacts in preventing recurrences of NGU are difficult to perform because of the possibility that patients might be exposed to an untreated or new infected partner and complete follow up cannot be guaranteed. It is most unlikely that these problems could ever be eliminated other than for short periods under special conditions. Other retrospective studies have failed to show that epidemiological treatment of sexual contacts of men with NGU helped prevent recurrences, but did not attempt to identify and exclude those with either male or female partners who had casual sexual contacts, who were thus at risk of reinfection from a third party. ${ }^{3-5}$ Those studies also assumed that patients not re-attending the clinic were free from recurrent disease, and two of the studies were conducted at centres where the population is probably less stable and the catchment population less well defined. Our study attempted to reduce these problems by documenting the sexual history of both partners to eliminate patients who could have been reinfected from a third party. Our results are biased towards patients returning with a recurrence of NGU, as we only admitted to the study patients who re-attended the clinic. From the results of our study we recommend the routine epidemiological treatment of all sexual contacts of men with NGU to reduce the likelihood of recurrences and help prevent the spread of the disease.

\section{References}

1 Wong JL, Hines PA, Brasher MD, Rogers GT, Smith RF, Schachter $D$. The etiology of non-gonococcal urethritis in men attending a venereal disease clinic. Sex Transm Dis 1977;4:4-8.

2 Taylor-Robinson D, Csonka CW, Prentice MJ. Human intraurethral inoculation of ureaplasma. $Q J$ Med 1977;46:309-26.

3 Fitzgerald MR. Effect of epidemiological treatment of contacts in preventing recurrences of non-gonococcal urethritis. British Journal of Venereal Diseases 1984;60:312-5.

4 Morton RS, Read L. Non-gonococcal urethritis: an investigation to determine factors in the host influencing response to treatment and recurrence of symptoms. British Journal of Venereal Diseases 1957;33:223-7.

5 Evans BA. Treatment and prognosis of non-specific genital infection. British Journal of Venereal Diseases 1978;54:107-11.

6 Adler MW. Diagnostic, treatment, and reporting criteria for nonspecific genital infection in sexually transmitted disease clinics in England and Wales. 1. Diagnosis. British Journal of Venereal Diseases 1978;54:422-7. 